
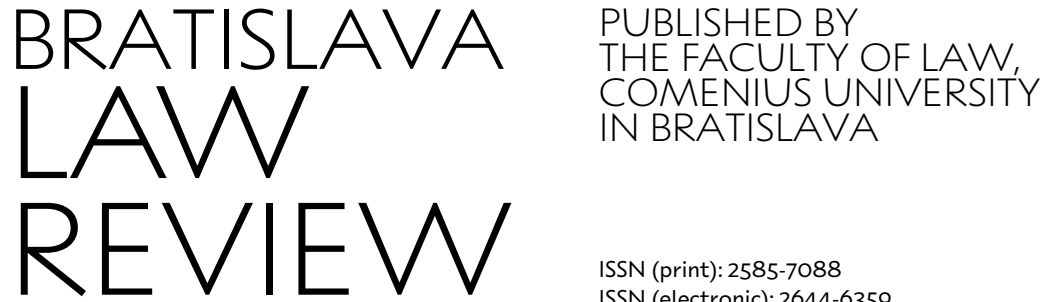

ISSN (print): 2585-7088

ISSN (electronic): 2644-6359

\title{
VISUAL AS MULTI-MODAL ARGUMENTATION IN LAW /
}

Marko Novak

\author{
Marko Novak \\ New University, European Faculty \\ of Law, \\ Delpinova 18b, Nova Gorica; \\ Slovenia. \\ marko.novak@epf.nova-uni.si. \\ ORCID: 0000-0001-8401-2567
}

Submitted : 26 May 2020

Accepted : 12 April 2021

Published: 30 June 2021

\begin{abstract}
Although the legal context is a formalized framework, in judicial proceedings there is also room for multi-modal argumentation. To the traditional logical mode, multi-modal argumentation theory has added three additional modes (the socalled "alternate" modes: visceral, kisceral, and emotional). They complement the logical mode in unclear legal cases, those with vague and ambiguous premises (both legal and factual). What is discussed here is visual argumentation as part of the visceral mode. Visual arguments can be appropriate in legal argumentation as evidence used to determine the lower premise. However, "thick" visuals invite alternate arguments to be applied in legal argumentation. This "invitation" is not exactly the same as with "thick" verbal texts because what is at issue are different semiotic resources.
\end{abstract}

Key words: visual argumentation; multi-modal argumentation; rhetorical argumentation; legal argumentation

Suggested citation:

Novak, M. (2021). Visual as Multi-Modal Argumentation in Law. Bratislava Law Review, 5(1), 91-110.

https://doi.org/10.46282/blr.2021.5.1.187

\section{INTRODUCTION}

The existence of multi-modal argumentation is far from a novel idea. The purpose of its creation was to extend the traditional logical mode of argumentation to other non-logical and generally non-verbal modes of argumentation (Gilbert, 1994). ${ }^{1}$ If a mode of communication is the manner or way in which people communicate, then the mode of argumentation will be the mode in which they argue, i.e. make claims and support them by reasons when they disagree. Apart from the logical mode, Gilbert also discusses the emotional mode, the kisceral (intuitive) mode, and the visceral (physical) mode $^{2}$ of which visual argument is a typical example. Within that theory, it is important that at least one premise (preferably reasons) is in an alternate (in this case, visceral) mode. This article deals with visual argumentation following Gilbert's theory of multimodal argumentation. Therefore, a visual argument will be the one in which at least one

\footnotetext{
1 Kress, a social semiotics scholar, even asserted that multimodality is "the normal state of human communication" (2010, p. 1).

${ }^{2}$ According to Gilbert, »these arguments are primarily physical and can range from a touch to classical nonverbal communication, i.e. body language, to force« (1997, p. 84).
} 
premise is visual. ${ }^{3}$ However, in my analysis of visual argumentation in law, I also borrow certain findings from another similar approach to the topic called multimodality (without a hyphen). ${ }^{4}$ Both claim their origin in social semiotics, which had invented the term multimodality that Gilbert extended to argumentation theory. Both approaches would agree that if argumentation is only in one mode, it is called monomodal, while a combination of more than one mode constitutes multi-modal argumentation (see, e.g., for the multimodal approach, Forceville, 2020, p. 65). With respect to real-life arguments, it is very rare to find them in one pure mode only. When combined, they are designated as "multimodal ensembles" (Kress and van Leeuwen, 2001).

An example of such a visual argument, used in the legal context, would be the video of the beating of Rodney King by the police (in 1991) (Groarke, 2017, p. 12). King was violently beaten by LA police officers during his arrest for fleeing and evading on a $L A$ road. A bystander filmed the incident from his nearby balcony and sent the film to a local news station (Koon and Deitz, 1992; King and Spagnola, 2012). The film clearly showed King being beaten repeatedly by the police. The structure of that quite clear visual argument $(P \rightarrow C)$ could be as follows: the conclusion $(C)$ : "King is being beaten brutally by the police" is supported by the premise $(P)$ : "Many harsh movements by the police officers hitting his body", where $P$ is in a purely visual (thus non-verbal) form. Thus, a quite clear visual evidence was appropriately interpreted (or "translated" from the visual mode) to form a verbal antecedent.

Yet the relevance of visual arguments for legal procedures and legal argumentation has not generally been discussed until relatively recently (Groarke, 2017). Visuals (such as photos, videos, etc.) have indeed been part of legal proceedings since their technological invention, and paintings, drawings, sketches, etc., had even featured before. They are mostly used in such proceedings in the form of evidence - because we do not have visual legal provisions, but have not been discussed as separate arguments, where their non-verbal form would be analyzed in the face of general legal arguments that are verbal. They have been more or less taken for granted in the frame of legal syllogism. Why this traditional neglect for them? Perhaps because (formal) logic has dominated the field and such visuals have simply been taken as evidence, which is part of the lower premise of a legal deductive syllogism, where the only question was whether such evidence meets a certain standard of proof prescribed for the specific legal proceedings. With the advent of information technologies, the internet, social networks, etc., visuals have become more important in human communication than ever before. It also became obvious that they cannot be just "automatically" used in the logical skeleton of typical legal argument, especially because of their different semiotic resources than words. Thus, problems have appeared that need to be addressed additionally to examine the possibility of traditional (i.e. logical) legal arguments being influenced by multimodality. From multi-modality, the so-called 'alternate' modes (i.e. emotional, kisceral, and visceral) are especially interesting, particularly in terms of seeing how they interact with the predominant logical mode in law, and what kind of dynamics they bring to the static character of traditional legal arguments.

\footnotetext{
${ }^{3}$ If there is some verbal text accompanying the visual, it may not change the point that the visual plays an important part in the argument. What is important is the view that the visual brings an additional dimension to merely verbal argumentation.

${ }^{4} \mathrm{~A}$ major difference between the two approaches is that, unlike the Gilbert's approach to multi-modality that discusses the four modes, multimodal theory of argumentation generally takes into account the following modes: visuals, written language, spoken language, bodily movement, sound, music, olfaction, taste and touch (see, e.g. Forceville 2020, p. 67). This approach generally falls within what Gilbert would call the visceral mode.
} 
However, before any discussion on multi-modality and law begins, it should be stressed that the legal context is a special social context in which a greater level of formality applies than in other social situations. Thus, special rules of substantive and procedural law are enacted in order for courts with mostly professional judges to decide upon the most important social disputes, so their decisions have very important consequences for the whole of society. Hence there is a need for these decisions to be properly made and reasoned and, therefore, the basic rule of the legal context emphasizes its strong institutional and normative constraints. If a legal dialogue is about communicating on the basis of legal norms, legal argumentation cannot be free from using them. Nevertheless, legal systems are not immune to interpretative problems such as gaps, vagueness and ambiguity. The findings from visual (and multi-modal) argumentation theory only contribute to the notion of legal indeterminacy. Or proves, once again, its argumentative not demonstrative agenda (Perelman and OlbrechtsTyteca, 1969, p. 13).

This article first discusses the existing formal constraints in law, in the form of legal provisions of a substantive and procedural character, which present necessary restrictions for any kind of multi-modal argumentative activity in that area. However, secondly, I analyze the importance of multi-modal visual arguments in the framework of legal argumentation, whereby I emphasize the role of visuals as evidence in the legal context, discuss the necessary semiotic "translation" ${ }^{5}$ of visuals into their verbal dimension, and point to a difference between thick and thin visuals. Thirdly, and finally, based on the theoretical model of the use of visuals in the legal context presented in the first part, in the second I reconstruct a real legal case in a multi-modal manner and present some final thoughts about the problem in the conclusion.

\section{FACING LEGAL INSTITUTIONAL CONSTRAINTS}

In (modern) law, seen as a separate social system of legal norms, people have traditionally argued on the basis of legal norms from statutory, constitutional, and executive regulations provisions as well as the case law of courts. As a result, specific legal arguments developed on the basis of legal texts, or at least in (close or more relaxed) connection with them. In this respect, Perelman and Olbrechts-Tyteca discussed the relevance of starting points (1969), and the pragma-dialectical theory of argumentation of institutional constraints (Feteris, 2017), in the case of law - legal provisions, the consideration of which is necessary in order to argue legally. ${ }^{6}$ This issue is of paramount importance for legal argumentation and disrespecting it leads to fallacious legal argumentation. The so-called "errors in law" include not only the absence of any legal provision referred to but, much more frequently, erroneous or improper legal norms being referred to in legal proceedings. Thus, in the context of law, the indispensable institutional starting points include both substantive as well as procedural legal provisions, since only both of them constitute complete legal texts as the necessary grounds in legal proceedings.

Moreover, logic and logical frameworks for making legal inferences and justifying them, whether they be simple or complex, have always been crucial for the legal world. This seems to be an axiom, at least regarding modern law. In order for the rule of law to apply, at least from the formal and internal point of view, in the context of the internal

\footnotetext{
${ }^{5}$ The quotation marks are used because no literal translation is applicable in this context, especially when unclear visuals are at issue.

${ }^{6}$ MacCormick would add that this makes "a restricted version of the arguable character of law" $(2005$, p. 17).
} 
justification of legal decisions (Alexy, 1989), the logical syllogistic argument seems to be an overarching form of legal argument. As a result, future legal practitioners are taught as early as in the first year of their schooling that the lower premise of the facts of a specific case must match the upper premise of a legal norm in order to come to a legal conclusion. However, in many legal cases, simple deduction as a method of formal logic does not suffice since as we have to additionally work on the premises (i.e. externally justify them (Alexy, 1989), often in the manner of informal logic. Accordingly, in the legal context, along with the deductive argument, which may even be called the "skeleton" legal argument, we could also add to such arguments of systemic, linguistic, historical or a similar character, to additionally explain the legal premise, and evidence to help establish the factual premise.

Considering the fact that not only typical logical and verbal arguments as traditional legal arguments can constitute arguments, but also other multi-modal arguments such as visual arguments, it is necessary to establish whether these alternate arguments can be valid ones in the legal context. In any consideration of this question, I should stress from the outset that, unlike general social communicative situations in which multi-modal argumentation can apply to its fullest extent, this is not entirely the case in the legal domain. As already mentioned, the law as a social subsystem has additional formal requirements, "starting points" or "institutional constraints." Therefore, this "golden" rule applies when we enter a legal discussion which also applies to legal argumentation: in order for discussion and argumentation to be valid in legal terms, one should argue by means of legal norms (legal rules and legal principles) only (or in connection with such). This follows from the overarching principle of the (modern) rule of law as the law based on legal norms.

To argue legally, one needs to assert a claim that is recognized by a legal norm: otherwise, his or her claim is rejected, and no legal argumentation ensues. The same rule applies to all participants in legal argumentation, whether they be parties, judges, prosecutors, or attorneys. All arguers and audiences participating in the legal discussion must follow this rule in order to make valid legal arguments.

But informal logic is still logic, albeit less formal and, given the described victorious position of the logical mode in law, why discuss multi-modal argumentation in law at all? Does this mean, therefore, that we need to discard its role in the legal domain altogether? I do not think so, but we will see below that by including multi-modal argumentation it becomes relevant in combination with legal norms as institutional constraints. And it might surprise us to see how uncertain a legal logical syllogism can be.

Still, to argue legally is to argue on the basis of legal norms, to subsume factual situations under them, and make legal conclusions. This is the basic requirement of the rule of law, as an ideal legal approach that is normative in character. Thus, visual arguments can also be appropriate in legal argumentation when, in a stronger or weaker manner, they are appropriately connected to legal norms. The previously mentioned video of King's beating by the police is an example of a visual argument within a broader legal argument whether such police's activity was unlawful. More specifically, the visual argument was found in the "battle" for the establishment of the lower syllogistic premise between the prosecutor and the policemen's defence counsel in that case. 


\section{VISUAL ARGUMENTS IN LEGAL ARGUMENTATION}

\subsection{Visual Arguments as Legal Evidence}

As already mentioned, if a visual argument is to be part of an acceptable line of legal argumentation from a legal point of view, it needs to be connected to relevant legal provisions and their application to relevant facts. When dealing with visuals as facts or evidence to be used in legal proceedings, visual argumentation becomes an inseparable part of legal argumentation. Let me refer below to an example of another visual argument reported by Groarke (2017, pp. 17-18), and see how it was applied as legal evidence used by the court in that case.

The so-called "Keane controversy" was about "the question whether Walter or Margaret Keane was the American artist who painted "big-eyed" paintings of children, women and animals that were popular in the United States in the 1960s. Although the paintings were originally attributed to Walter, Margaret claimed that she was the real artist in 1970, initiating a long dispute. When she sued Walter for \$3 million in 1986, the case was tried in the federal court in Honolulu. In an attempt to determine who the real artist was, Judge Harold M. Fong asked Margaret and Walter to paint a big-eyed child before the court [consisting of the judge and the jury]. While Walter claimed he had a sore shoulder and could not paint, Margaret painted a young boy in the manner of the wellestablished paintings. The painting became Exhibit 224 and, together with other considerations, it produced a judgment that awarded Margaret \$4 million in damages. Margaret's act of painting was submitted as [non-verbal] evidence for the conclusion that she was the artist who painted the well-known big-eyed paintings." (Groarke, 2017, pp. 17-18).

The visual argument in that case reads as follows: Claim - Margaret's painting painted before the court is (almost) the same as the previous "big-eyed" paintings; Reason - [the painting itself], is an example of the non-verbal visceral mode.

This is not exactly the same as the legal argument in the logical mode, which was made previously in the lawsuit, and went in the following manner: Mp (the major premise consisting of legal norms): "Anyone whose copyright is violated, is to be redressed concerning their moral (recognizing authorship), or material rights (awarding compensation), respectively." In the Mp, copyright holders could be defined to include painters (a), as well copyright violations to include false authors pretending to be original ones (b). At the level of the factual premise of the legal argument, we have mp (the minor premise consisting of relevant facts) which reads in the following manner: "Margaret's copyright was violated since she was proved (by the evidence taken in the form of Margaret's painting before the court - the visual argument in that case!) to be the original author whose authorship had been stolen." Finally, what follows is c (the conclusion inferred on the basis of the minor premise subsumed under the major premise): "Margaret's copyright is to be redressed."

Thus, the above-mentioned visual argument (of Margaret's painting before the court) was used as legal evidence to prove the existence of the minor premise in that case so that the deductive syllogistic inference was possible by applying the relevant copyright provision to the described facts. By means of this evidence it was proved that Margaret was the original author, which meant that Walter stole the authorship of bigeyed paintings from her.

The use of visual arguments as legal evidence in legal cases has been commonplace for quite some time. With technological development, our societies have very much become visual, which means that the use of visual arguments will only increase. However, their use in legal proceedings to date to prove the existence of certain 
facts so that specific legal provisions are applied has been taken for granted somewhat. Here I try to show that this should not be the case as there are different visuals, some with multiple meanings discovered not until they try to be interpreted. And, what is important, we do not face exactly the same problems as when words are interpreted. As semiotic resources, visuals are different from words and never completely (or literally) translatable by them. Both visual and verbal arguments in their monomodal forms might be already complex, not to mention their multi-modal (visual-verbal) combinations. Thus, in the process of their use in legal proceedings in such a case, there seems to be plenty of room for different strategies that lawyers might use in order to persuade their audience about their positions.

\subsection{Semiotic "Translation"}

To qualify arguments which are constructed in everyday life as visual, they need to be made in a visual mode, where their reasons/premises are (non-verbal) visual, such as pictures, paintings, photographs, videos, drawings, sketches. As a matter of fact, it would be quite unusual if not impossible to find pure visual arguments. They are usually accompanied with some (verbal) text (in a premise or conclusion) and are in fact already as such multi-modal. In semiotics, it is held that every image (or visual) is polysemious (has multiple related meanings). Thus, the role of the verbal text accompanying a visual is to anchor and relay it. Anchoring helps to control it, by avoiding other meanings and keeping it away from any emerging connotations, while relaying is to fill the gap that the images cannot (Barthes, 1967).

However, in order to be used in a legal argument, in the case of evidence to enter the minor premise of a legal deductive syllogism, they need at some point to be verbalized. There are several reasons for this: legal provisions with possible sanctions for their violations are in a verbal form, the evaluation of evidence with all discussions in the courtroom is verbal. Such is the verbal justification of their application with a proper analysis in the reasoning of a judgment in such a form. Before such an inference is made, a legal norm has to be extracted from a relevant legal provision in view of the applicable facts, as well as legal facts extracted from brute, in this case visual, facts (supported by evidence) on the basis of the legal norm. Engisch illustrated the interdependence between the normative legal text and the description of the case with his metaphor of "looking back and forth" ("Hin- und Herwandern des Blicks")( 1963, p. 15).

Therefore, a visual (e.g. evidence) needs to be translated into a verbal form to be subsumed under a verbal legal norm. However, as Kjeldsen notes, literal translation between different multi modes is impossible (2015). ${ }^{7}$ The verbal means do not actually suffice to capture the rich information communicated by images to an audience (Kjeldsen 2016). However, some kind of semiotic translation of visuals into words is therefore necessary in the legal context, despite the fact that it constitutes something of a "leap." Translations across modes, for example from image to speech, are both possible and difficult and always achieved with enormously difficult selection, at a considerable level of generality (and in inevitably significant changes in meaning) (Kress 2010, p. 10). Blair claims that the verbal is to be understood as a placeholder for the visual, not a "translation" of it: verbal reconstruction rarely captures all that was expressed in the visual argument, but is a placeholder for it, and provides us with a reference for use in evaluating the cogency of the visual argument (2015, p. 220). Therefore, there is a risk of overemphasizing the role of the verbal over the visual by using merely linguistic properties

\footnotetext{
${ }^{7}$ Which Jung also claimed for his four cognitive functions (1971).
} 
to assess the visual because some important features of images may remain outside of the linguistic perspective (Tseronis and Forceville, p. 15).

When the verbal mode is combined with the visual mode, it is wrong to assume that the verbal model conveys the standpoint while the visual mode is only the reasons in support of it, so that, it is simply used to appeal to the audience's emotions (Tseronis and Forceville, p. 15). The meaning conveyed by texts in which more than one semiotic mode is at play is never the sum of distinct parts of a multimodal text (Jewitt, 2014). The meanings of one mode and the meanings of others resonate so as to produce more than the sum of the parts (Bateman, 2014, p. 6).

But the "translation", whatever it may be, from the visual into the verbal logical mode is necessary in the context of legal argumentation. Otherwise, there is no way of confronting legal evidence in the visual form with facts that need to be in the verbal form so that a relevant legal provision is applied in a verbal form. Legal arguers need to "translate" their alternate arguments into the logical mode, the "language of legal norms and legal systems", to pass muster in terms of the rule of law.

In this case, a "semiotic translation" implies that various non-verbal 'semiotic resources' (or speech acts (Groarke and Tindale 2004)) need to be "translated" in the verbal mode in order to play some role in legal proceedings. This not only applies to visuals, such as pictures, photos, etc., but also to other physicalities from the visceral mode, including sounds, tastes, smells, although in this paper I limit myself to visuals. In certain cases, there is no problem with this since visual "reasons" can be more or less easily "translated" into (legal) words, about which there would be no major disagreements in the relevant legal community because the premises would be considered as clear. In such clear cases, the "translation" is unproblematic. As such, I refer below to semantically thin visuals (see also Kjeldsen, 2015). There are also other types of cases, where such a "translation" is far from smooth. In such cases, bridging a gap between the alternate modes and the legal logical mode is controversial due to various reasons, both visual and verbal. I call such visuals semantically thick ones (see also Kjeldsen, 2015). Kjeldsen calls the enthymemes, referring to a rhetorical syllogism in which either the premise(s) or the conclusion is left to be completed by the audience that has the task of "filling in the blank" by having recourse to contextual information (2017).

\subsection{Semantically Thin, and Thick Visuals Inviting Alternate Arguments}

The difference between semantically thin and thick visuals is reminiscent of the distinction between a figurative and abstract painting. When you sit in a gallery in front of a still-life painting, your thoughts would perhaps travel less far than in the case of an expressionist painting, although one would expect that figurative paintings, as works of art, would be still stronger in their messages than unclear legal texts, which have an institutional tendency to be as precise as possible.

Clearly understood visuals are semantically thin, which means that they do not invite different interpretations ("translations") from those that interpret them. In such cases, we can expect quite easy "translation" from their visual to the verbal mode. This means that there would be no substantial gap between the two modes. Recall that the example of the video of the Rodney King beating from the very beginning of this paper. Also, I mentioned that the prosecution and defence could have argued about the "translation" of the video. In fact, it was not very much disputed because the filmed beating of Rodney was quite clear. In such a non-problematic case, the visual mode and its reasons were easily "translated" into the verbal mode of the minor premise, thus producing the following figure: 


\title{
Figure 1: Easy "Translation" of Thin Visuals
}

\author{
Vr eT mp
}

\author{
Legend: \\ $\mathrm{Vr}=$ visual reasons \\ $\mathrm{mp}=$ minor premise \\ eT = easy translation
}

However, when it comes to unclear cases, one possibility is that legal premises are indeterminate: e.g. ambiguous, ${ }^{8}$ or vague, ${ }^{9}$ and need to be interpreted (in the narrow sense $)^{10}$ in order to be properly applied. But the problem can also be with the unclear factual premise. In our situation, this would apply to unclear visuals as evidence in the legal context, which are semantically thick. Consequently, the interpreters ("translators") of such evidence, arguers and audiences, would evaluate them differently, based on what meaning they glean from them. Therefore, because of unclear visuals, problems occur with their verbalization, i.e. "translating" them into the verbal mode. Thus, the following figure of a hard "translation" might apply:

\section{Figure 2: Hard "Translation" of Thick Visuals}

\author{
$\operatorname{VrhTmp}$
}

$$
\begin{aligned}
& \text { Legend: } \\
& \hline \mathrm{Vr}=\text { visual reasons } \\
& \mathrm{mp}=\text { minor premise } \\
& \mathrm{hT}=\text { hard translation }
\end{aligned}
$$

In the event of thick ${ }^{11}$ visuals being used as evidence to determine the legal facts, arguers and audiences have more room to rely on elements from outside the immediate legal framework, such as their personal values that they can read into the premises. This is more difficult when it comes to thin visuals in clear cases, where their perception and thus also evaluation are semantically narrowed down to a greater extent than in unclear

\footnotetext{
${ }^{8}$ By ambiguity in law I mean that a legal provision has several, at least two, meanings. For example, in Smith v. United States, 508 U.S. 223 (1993), the provision of Title 18 U.S.C. 924(c)(1) requires the imposition of specified penalties if the defendant, "during and in relation to ... [a] drug trafficking crime [,] uses ... a firearm." In that case the defendant offered to trade an automatic weapon to an undercover officer for cocaine, and the mentioned provision could have been understood in two possible ways: (a) the use of the firearm for the purpose of exerting force or violence concerning sellers of drugs or third parties who would prevent the deal; or (b) the use of the same as a good or payment method.

${ }^{9}$ I consider a legal provision 'vague' when it is very general. An example of such would be e.g. general legal principles ('rule of law') and general legal standards such as 'public interest,' 'reasonable person,' etc.

${ }^{10} \mathrm{Here}$ I subscribe to the 'narrow' definition of interpretation, according to which we interpret legal provisions only when they are unclear (Wróblewski, 1992). Otherwise, we merely "apply" them to legal facts.

11 If 'clear' can be associated with 'thin,' 'unclear' is not necessarily 'thick,' because thick would imply several meanings whereas unclear might entail none.
} 
cases. In such cases, there are several possible interpretations of a thick visual and this means that arguers have more potential to be effective in suggesting their version of a reasonable interpretation to their audience.

The situation where thick visuals are used as evidence and invite several possible meanings for judges to consider is semantically quite similar to the problem of unclear texts, where the values of judges can also be discerned in their rulings. Thus, there would be no single answer but several possible directions, a factor which is often manifested in divided courts with the opinions of different judges on the table.

In this respect, semantically thick (legal) words, being part of the logical mode of the upper premise, present similar problems than thick visuals (as part of visual argumentation preceding the establishment of the lower premise). They both invite alternate modes of arguing (i.e. emotional and kisceral being intuitive arguments such as personal values), as not strictly legal materials in a legal case, to fill out "blank" (logical) legal arguments (see also Novak, 2020a, 2020b). Arguers such as judges are embedded in their social and psychological environments that they share with their audiences, and the legal logical mode through their arguments is only able to generalize clear legal situations. Since "a picture is worth a thousand words", it seems that (thick) pictures create greater semantical gaps than (thick) words, and when the two of them are combined the semantic problem is even exacerbated.

Thus, when visuals are part of legal argumentation, the visual and verbal modes interact. There are a number of different situations that can make the case clear or unclear. Already at the level of visual argumentation, there could be thin or thick visuals, which can also be accompanied by a thin or thick verbal text. Generally, a thin verbal text would anchor a thick visual, which could not be the case with a thick verbal text in combination with an either thin or thick visual. This becomes even more complex when visual argumentation enters legal argumentation, with the upper (legal) premise being represented by thin or thick words. Imagine "translation" and interpretation problems when thick visuals meet thick texts of legal norms.

Below, I present an unclear case with a thick visual, where the evidence provided an opportunity for judges to use different (multi-modal) argumentative-rhetorical moves to justify their decision on the case at hand.

\section{A CASE ANALYSIS: GRIMS V. MLADINA}

\section{1 Facts and Legal Procedures}

In March 2011, Mladina, a Slovene left-wing weekly, published the following photos entitled "Not Every Dr G. is Already Dr Goebbels"12 in its satire feuilleton (Mladinamit):

\footnotetext{
${ }^{12}$ Capital letters in the Slovene original.
} 


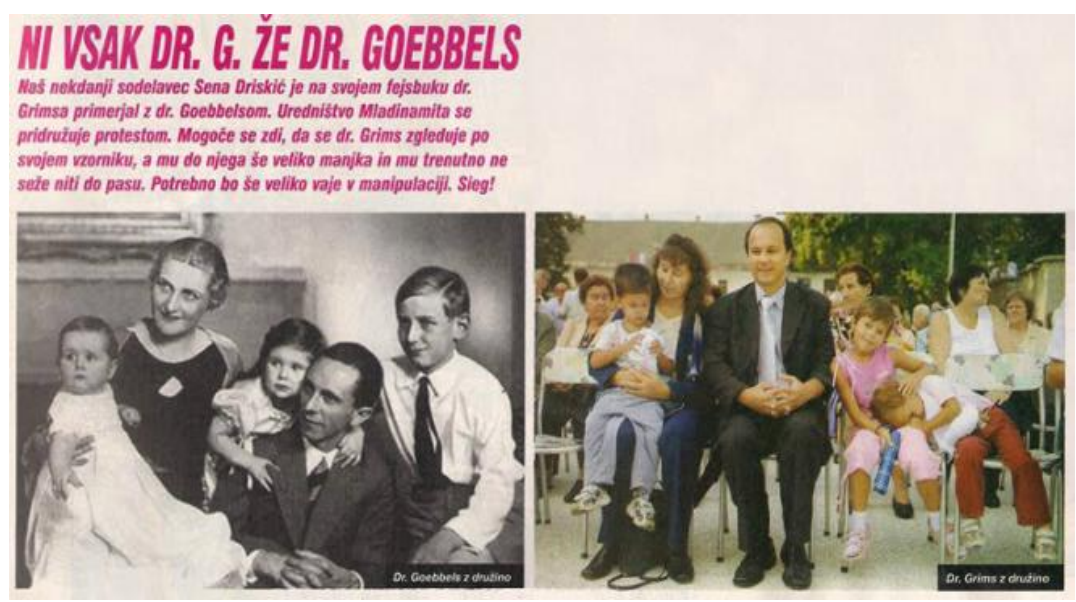

Underneath the headline, the two photos were accompanied by the following text: "Our former associate, Sena Driskić, compared Dr Grims with Dr Goebbels on his Facebook profile. The editors of Mladinamit join his protest. It might seem that Dr Grims follows his role model, but he still lags behind him. He needs more training in manipulation. Sieg!"

In the editorial introduction of the same magazine, and in three texts of the following edition, Mladina's editors commented as to why they had made the comparison between Mr Grims, a prominent right-wing Slovene politician, and his family, with the family of $\mathrm{Dr}$ Goebbels, the Nazi minister of propaganda. They wanted to criticize Mr Grims' activities of political propaganda that largely focused on manipulating the general public, of which his latest reports about an alleged imminent threat from migrants to Slovenia were particularly bad examples.

Grims then sued Mladina before the District Court, which dismissed the lawsuit in July 2013, reasoning that Mladina criticized Grims' political activities to a justifiable extent in the manner of political satire. The court stressed that Grims took advantage of the media for his political promotion in the same manner as Goebbels. There was allegedly no direct comparison between the two families and both the pictures must have been understood in a broader context, together with the accompanying text.

Grims appealed and the appellate court reversed the first court judgement in February 2014 (No. I Cp 3057/2013), ordering Mladina to publish the judgement, apologize to Grims, and awarding him damages. The court reasoned that: "The publication of photographs can encroach on people's integrity more severely than words." They even mentioned the idiom "A picture is worth a thousand words". They continued: "Although the freedom of expression includes publishing photographs, when courts balance various interests or the freedom of expression against personality rights, they may need to separate the text from the published photographs, and make a separate balancing of the opposite interests in connection with the photographs." To support their reasoning, they cited ECtHR's Rothe v. Austria. ${ }^{13}$ They added that photographs and

\footnotetext{
${ }^{13}$ There are certainly other cases in which the ECtHR did not evaluate pictures separately but in the entire context of the case. See, e.g., Wirtschafts-Trend Zeitschriften-Verlagsgesellschaft m.b.H v. Austria, which the Slovene Court did not consider relevant in this case.
} 
pictures cause multi-layered effects and highlighted the openness of non-verbal communication. Thus, in their opinion, journalists must be more careful when dealing with pictures and photographs. Moreover, despite the fact that Grims was a crafty politician, he was also the father of a family, and the journalists' criticism went way beyond the limits of a reasonable critique by comparing him with a mass murderer, who also agreed to poison all of his 6 children at his wife's behest.

In the judgement rendered on 10 September 2015 (No. II Ips 93/2015), the Supreme Court affirmed the appellate court's judgement. They reasoned that the photographs in that case, as a separate totality, went beyond the limits of the comparison of the methods of propaganda used by Grims and Goebbels. What was crucial was the comparison between the ideal family life demonstrated in both the photographs and the fact that the Goebbels had killed all of his children. In the judges' opinion, any criticism should not be more vulgar, insulting, intimidating and less dignified than the political activities criticized.

Mladina subsequently appealed to the Constitutional Court, which upheld (by Decision No. Up-407/14 dated 14 December 2016) the Court of Appeals' and the Supreme Court's decisions. They emphasized the general power of pictures (also emotional) and agreed to the separation between the photographs and the text when balancing the freedom of expression against the personality rights by the lower courts. They reiterated that the image of the father of a family during an Assumption-Day mass at Brezje, Slovenia's most famous pilgrimage site, should be protected from a comparison made with a mass murderer in another photo. The case was decided by seven votes in favor and two against. The dissenters pointed to the fact that the political satire in that case should have been protected under the constitutional freedom of expression, and that the majority erred when protecting the right of a father to safeguard the collective reputation of his family, which was allegedly not even argued in the case.

\subsection{A Multi-Modal Reconstruction of the Case}

To what extent is the above case multi-modally relevant? Was it not decided upon solely on the basis of the (legal) logical and verbal mode? Where can we discern the traces of multi-modal argumentation in this case?

In the process of justification, judges would usually be reluctant to admit that they are also - as other people normally are - trapped in a hermeneutic circle, as in their reasoning they would only say that they apply "objective" criteria. Therefore, judges' separate opinions would promise more materials for discerning their subjective views than majority ones whose style is generally more official. It is thus the task for legal academics in particular to reconstruct their decisions in a multi-modal way, along with the standard argumentative reconstruction of legal decisions as suggested by mainstream legal argumentation theory, which is usually concerned with what kind of legal arguments were used in legal decisions and whether they could be used in a better, that is more rational/reasonable, manner. This additional kind of 'multi-modal reconstruction' as suggested here will extend the mainstream argumentative reconstruction of the reasoning of legal decisions further. In contrast with mainstream reconstruction, the multi-modal reconstruction of legal, mostly judicial, decisions would follow a different aim than the mainstream reconstruction. It could be used as an additional tool to study the potential for multi-modal arguments and rhetorical devices to be used and would be secondary to typical legal arguments. It would provide us with additional information which would allow us to obtain insights into the argumentative and rhetorical colourfulness of the environment in which the legal logical mode is used. 


\subsection{Logical and Visceral Argumentation}

Lawyers used to the (legal) "robust" logical ${ }^{14}$ (and verbal) mode will take such a case for granted. They would reason that there were simply two different legal positions in that case and one of them prevailed. However, a careful eye which is able to perceive the subtleties of multi-modal details will perhaps see such a case in a different light, finding both the premises indeterminate (the major vague, and the minor ambiguous due to the thick visual based on which that premise was established differently, at different court levels and by different judges).

First, the relevant legal norms (in the universal premise - Mp) in the case, as the logical mode's substance, in this case, were on one hand from the Code of Obligations (at the level of ordinary courts' procedures) and Art. 35 of the Constitution (the right to the protection of integrity and reputation, on the level of constitutional review). They provide the grounds for legal redress if one is "defamed by another person." On the other hand, Art. 39 of the Slovene Constitution, which was also potentially relevant, ensures "freedom of expression," which at the level of constitutional review failed to overrule the right not to be defamed as a personal right. Both Mps in this case are quite vague: on one hand, we have freedom of expression protecting political satire while, on the other, we have the father of a family who took them to mass and for that reason is compared with the family of one of the worst Nazis. In the whole procedure, it was unclear which position would ultimately succeed: on one side, there were the positions of the District Court and the Constitutional Court's dissenting minority, on the other the court of appeals, the Supreme Court, and the Constitutional Court's majority. This was certainly not visual vagueness or "thickness", but normative-legal. Constitutional norms, such as the freedom of expression and personality rights as applying in this case, are generally thick, and their balancing even contributes another dimension to their thickness. ${ }^{15}$

Second, in terms of the factual (particular) premise which was presented at the level of the constitutional review as challenging the court decision, the photographs were presented in the magazine in the visual (or visceral) mode, with a scant verbal explanation about the comparison. The text that initially accompanied the photographs tried to anchor them, obviously unsuccessfully as determined by the senior courts. Frankly, the initial verbal text published above the photographs was quite ambiguous (thick), whereas the editors' additional comments made the anchorage firmer by pointing to the reason why the politician was criticized in the mentioned manner. The final anchor had been accepted by the first-instance court, however not by the higher courts that retrieved it in order to make the photographs' comparison thick (again) in order to open the gate for them to introduce the argument/value of the reputation of a family father, as a personality right to be protected against the journalists' freedom of expression. Thus, the thick image "translated" in the said manner was then placed in the thick framework of balancing the two constitutional norms. The visual comparison of the two photographs was striking to the extent that the verbal anchor used could not achieve its purpose. However, the Constitutional Court's dissenting judges would share the same opinion.

In order for the photographs to be classified as legal facts subsumed under the relevant legal norm, despite some small verbal text, they needed to be "translated" to the verbal mode as a legal position pointing to the existence of (no) defamation. Notwithstanding the aid of such a "translation," the photographs compared were "thicker"

\footnotetext{
${ }^{14}$ What is typical for the legal logical mode are the: (a) form of logical argument (most frequently deductive syllogism), and (b) substance inclusive of legal norms (rules and principles) being the core of any legal system. 15 Some theorists do not list the argument of weight or balancing among interpretative legal arguments, but among constructive legal arguments (e. g. Guastini, 2014, p. 407).
} 
(Kjeldsen, 2015) than the words that tried to anchor them. Indeed, the judges made them such (i.e. thick) when they retrieved the verbal anchor used and found the personality right of the family father to be protected. Due to the vague legal provisions and the judges' divergent reasons with respect to the evaluation of the comparison of the two photos, the decision cannot simply be taken for granted as a kind of "neutral" application of the law. Thus, the case could have been understood in two different manners, by seeing either a crafty politician who deserved to be criticized (the lowest court and the dissenting minority) or an exemplary father who was worthy of protection (all the other judges). The case was not only normatively thick (vague) but also factually thick due to the thick visuals as evidence to determine the factual premise in this case.

Apart from the visceral mode, the kisceral mode as well as the emotional mode must have been relevant in this case. To see Mr Grims also as a father and not only an annoying politician necessarily entails that one should resort to family values and the father as a family protector. The judges expressed this openly when they stressed the importance of a comparison of the photographs in isolation from the accompanying text, which they said was an example of an admissible political critique. Also, the Nazi horrors that they despised and the family relations that they cherished, as emotional arguments - as used, certainly, in the "safe harbour" of legal logical syllogism, were also expressed by the judges. ${ }^{16}$

Therefore, in this case, the visceral argument ( $\mathrm{C}$ - The Grims and Goebbels being two similar families; $\mathrm{R}$ - Their photos being published together) opened up room for other alternate arguments to step in, in the absence of a more precise argumentative framework concerning the comparison and given the vague legal provisions which applied. Thick visual evidence (actually, made thick by the courts) from the lower premise have met the thick words of the upper premise. But that is a typical situation in hard legal cases - in clear or easy cases, their premises tend to be clear. Consequently, the positions of the two judges were possible in that case: (a) if the comparison is considered in the context of the whole story, and Mr Grims were looked upon more as a prominent politician, then the political satire account would be supported; whereas (b) if the photos are taken separately from the text, his role as a father figure would be protected.

\subsubsection{The Kisceral Argumentation of Values}

In a hermeneutical situation, one which is all the more so apparent when unclear legal cases are resolved, what is important are also judges' inner (personal) ${ }^{17}$ values that include both their intuitions and emotions. It is well-known that neuroscience and cognitive psychology connect cognition with emotions when values are psychologically experienced. According to Thagard, "values are mental (neural) processes that are both cognitive and emotional. They combine cognitive representations such as concepts, goals, and beliefs with emotional attitudes that have positive or negative valence" (2013). In the view of Oyserman, "values can be thought of as priorities, internal compasses or springboards for action". They are "implicit or explicit guides for action, general scripts framing what is sought after and what is to be avoided", and "ultimate rationales for people's action". They are at play on both the individual and group levels. Even at the individual level, they are internalized social representations or moral beliefs that people

\footnotetext{
${ }^{16}$ About the role of intuition and values, and their connection with emotions, see more below.

${ }^{17}$ Here I use the adjective "personal" (meaning subjective) because values in law can also be objective: as part of legal provisions such as, e.g., equality before the law and legal certainty that are in fact constitutional provisions.
} 
appeal to and are internalizations of sociocultural goals. "Values are not simply individual traits: they are social agreements about what is right, good, to be cherished." They contain cognitive and affective elements and have a selective or directional quality being internalized (2001).

Values most often give judges indications as to how to further construe legal premises. As already mentioned, as a rule, they are not directly and openly expressed in the written materials of judges' deliberations or their reasoning. Yet this is not to say that they were not present, and sometimes in a very influential manner. It seems that the less legal premises are determined, the more room there is for them to step in.

It should be stressed that for Jung, but also contemporary psychologists interested in cognitive science and neuroscience who base their findings on numerous experiments with human brain activities, there are two types of thinking - "fast" or automatic and "slow" or analytical, also termed System 1 and System 2 (Kahneman, 2011), which are very much related. Fast thinking relies on emotions and intuitions, to which I would also add physicalities, for which the right hemisphere of the brain is "responsible". In human evolution, this is the older part of the brain while slow thinking, which is more rational or what some call critical thinking, is more logical, analytical, technical and developed later in evolutionary terms. When it comes to multi-modes of argumentation, I would ascribe the (legal) logical mode to System 2, and other alternate modes to System 1.

Accordingly, in connection with the above-mentioned two systems of thinking, the problem with unclear cases is the following. In clear cases, as their counter examples, the premises of legal syllogism are very much developed, and in a modern legal system they are expected to be analytically, coherently, logically interrelated, and connected so that the principle of legal certainty is upheld. We could say that this an expectation for System 2 to operate. However, when there are gaps, ambiguities, and vagueness in the premises in the legal context of judicial proceedings, there is more room for System 1 to step in and direct the manner in which System 2 develops. This is an opportunity for values to step in for the initially unclear legal premises and do the job for them. A typical example of such is a constitutional review in which the clashes of values are commonplace because there are different judges with different worldviews.

Moreover, Mercier and Sperber claim that most reasons are "after-the-fact rationalization". Their main role is to "explain and justify" our intuitions but not in the process of intuitive inference itself. They are social constructs and are meant for social interaction, having "a central role in guiding cooperative or antagonistic interaction, in influencing reputations, and in stabilizing social norms." They continue that "the way we infer our reasons is biased in our favour. We want reasons to justify us in the eyes of others." And "they represent our inferences as rational in a different, socially relevant sense of the term where being rational means being based on personal reasons that can be articulated and assessed. To be socially shared they need to be verbally expressed" (2017, p. 110-144).

It was Kelsen who said that "the interpretation of a statute, need not necessarily lead to a single decision as the only correct one, but possibly to several, which are all of equal value, though only one of them in the action of the law-applying organ (especially the court) becomes positive law". Kelsen asserted that when legal practitioners interpret laws by means of their cognition (logical and rational), ${ }^{18}$ they could only establish what the frame of that law is and within it, there are "several applications possible". He

\footnotetext{
${ }^{18}$ Compare this with Jung's interpretation of cognition, which includes the irrational functions of perception, sensation and intuition.
} 
contrasted his view with traditional jurisprudence, which claimed that it had found legal methods of how to correctly fill in the ascertained frame. He continued that "[t]raditional theory will have us believe that the statute, applied to the concrete case, can always supply only one correct decision and that the positive-legal "correctness" of this decision is based on the statute itself". Further, it would seem "as if the law-applying organ had to use only his reason but not his will, and as if by a purely intellectual activity, among the various existing possibilities only one correct choice could be made in accordance with positive law." ... "All possible methods of interpretation developed so far lead only to a possible, not necessary, result, never to one which is alone correct." Thus, "it is futile to justify "legally" one at the exclusion of other." In such "it is not cognition of positive law, but of other norms that may flow here into the process of law-creation - such as norms of morals, of justice, constituting social values which are usually designated by catch words such as "the good of the people", "interest of the state", "progress," and the like" (1989, pp. 351-354).

Kelsen understood the problem that I indicate here perfectly. His criticism of apparently "legal" argumentation seems to refer mostly to the so-called unclear cases. In clear cases, his critique is, I must say, exaggerated. His conception of the legal "mode" is, however, close to what I understand here by the "legal logical mode": mostly legal norms of positive law composed in a body of laws that we call the legal system.

Thus, if legal premises are vague and ambiguous, which is a rule in unclear cases, there is room for values or arguments of values to have their say. They are not part of the traditional legal logical mode and thus, when basing their decisions and reasons on values, judges in unclear cases would argue that what they apply is strictly law, and that their reasons and arguments necessarily only follow from the legal text. This should certainly be criticized as it makes decision-making and reasoning less transparent by leaving out something that is tremendously important. In such cases, judges should admit that what they do is also legal policing and moral legislating, since the values behind their "legalistic" activity can be of moral, social, and political importance for their community.

Also, if factual premises are vague and ambiguous due to thick (visual) evidence to determine such, there is room for judges' values to step in. Thus, having both premises unclear complicates the case's argumentation even more. In the case at issue, provided the unclear upper premise(s), the judges retrieved the journalists' verbal anchor from the photographs compared, just to resort to the value behind the mentioned personality right of the family father that they disclosed and then protected.

Based on the above theoretical discussion of the importance of judges' values, can we discern them in the text of the reasoning of the decision? The perception of values as internal mental representations is to a great extent connected with intuition. This is the reason why the kisceral mode of argumentation is discussed, and this mode of argumentation is relevant for legal argumentation when legal arguers base their legal arguments on the values that they subscribe to. Certainly, these values need to be recognized by the legal order, however, it would be difficult to find a major value that has not been embedded in the constitution as the supreme legal act of a certain society. These values are directly referred to, or at least implicitly incorporated, in specific constitutional legal norms.

Well, it certainly follows from the majority reasoning of the decision that it explicitly emphasized the value of a father-protector image, which the majority recognized from the photograph of Grims and his family. Jung would explain that, apparently, the father archetype was well integrated into the majority of judges' personalities. His family role, or the role of a "family father" who wanted to protect the 
reputation of his family by suing the magazine, seems to be more important to them than the value of free speech, in which criticizing a prominent politician for his political activities is an important liberal value in limiting government and individual freedom. Moreover, the fact that Grims was the father of a religious family at a religious ceremony contributed further to protecting conservative values in society.

In the mentioned case, the kisceral argument read as follows: $\mathrm{C}$ - the value of a family (and family father) was violated; R - the photographs (in which an ideal Grims family was compared with the Nazi family). That kisceral argument was read into the following constitutional argument: $\mathrm{C}$ - the personality rights were unconstitutionally violated; $\mathrm{R}$ - when balanced against the freedom of expression, the personality rights were too much interfered with. However, the case was not decided kiscerally only but in an important connection between the kisceral and legal logical premises.

\subsubsection{Emotional Argumentation or Rhetoric in the Case}

In this case, in their "sober" logical reasoning, the judges used a number of emotionally loaded words to support their rejection of the photos' comparison, which is a proof that they resorted to certain emotionally loaded rhetorical devices, in order to be more persuasive in relation to their audience. They used the following emotional words: the "horrible" contradiction between ideal family life and "cruel" historical evidence; a "shocking" comparison; a general symbol of "evil"; the metaphorical dimension of "bestiality".

Despite the fact that emotions are very important in people's lives and in the (professional) activity of legal arguers and audiences, in this kind of research, where I examine lawyers' and judges' reasoning in the written text, one cannot expect them to enjoy a greater role. In justifying their decisions, lawyers rely on legal provisions and their reasonable interpretation. Emotions are rarely found, mostly only in the judges' separate opinion when they get more personal and sometimes make use of emotional rhetorical devices. I do not deny that another study, perhaps a psychological one which tries to get into the mind of judges, or a study focusing on the psychological dynamism in a courtroom where also a jury is involved, would prove that they have a greater role.

Emotional argumentation in that case would read as follows: $\mathrm{C}$ - the judges' emotions hurt; R - the photographs compared: the "horrible" contradiction between an ideal family life and a "cruel" historical evidence; a "shocking" comparison; a general symbol of "evil"; and the metaphorical dimension of "bestiality". This is not what one would suspect that the judges felt when seeing the comparison of the two photographs, but that is what they wrote in the text of the Constitutional-Court decision and can be found there as their rhetorical devices used, which may also have an argumentative value (Perelman and Olbrechts-Tyteca, 1969). As already mentioned, neuroscientists admit that perception of values is intuitive-emotional, thus when confronted with the photographs' comparison, they used the kisceral and emotional arguments to read them into the legal arguments.

Accordingly, was the use of the said emotional figures rhetorical or argumentative? I guess both aspects are possible. Rhetorical argumentation theorists claim that rhetorical figures (such as emotional figures used in this case) may be argumentative if they bring about a change of perspective and the adherence of the hearer (senior judges or other audience members); if that is not the case, they will be considered as an embellishment or a figure of style (Perelman and Olbrechts-Tyteca, 1969, p. 169). 


\section{CONCLUSION}

The presentation of problems associated with the legal interpretation of visuals as evidence used to determine the factual premise, and how that interacts with the legal premise, seems to be innovative and important for legal argumentation scholarship. These relevant nuances seem to have been neglected so far.

When legal reasoning is taken descriptively, Beck claims that, apart from its scientific model in which judges follow legal topoi (such as legal provisions, established arguments and methods of interpretation and argumentation), we also need to consider its heuristic (non-formalist) model with extra-legal steadying factors (of a moral, economic, or political character) (Beck, 2012, pp. 24-27). These extra-legal steadying factors include a judge's need to attract public confidence in their judgments; the fact that they can(not) be always absolutely politically constrained and judicially selfrestrained; their inclination to be politically fashionable and correct; adherence to their professional and institutional ethos that have particular characteristics; and an inability to always neutralize their personal elements (such as their personal beliefs, values and interests) when making and justifying their judgments (Beck, 2012, pp. 35-50).

The combination of the scientific and heuristic model to some extent converges with my multi-modal approach to legal argumentation. Firstly, there is a more formal framework for the logical mode. Secondly, there is also a multi-modal argumentative dimension of legal reasoning. It is this rhetorical aspect of argumentation (Tindale, 2004) that brings legal arguments closer to the real life of arguers and their audiences. When legal argumentation is taken as rhetorical argumentation, we not only recognize logical arguments (logos) but also kisceral (ethos), emotional (pathos), and visceral (physis) that arguers use in order to persuade their audiences (Novak, 2020a).

The mentioned approach is not a theoretical speculation but is built on analyzing the justifications of legal/court decisions. Beck's, as well as multi-modal "alternate" modes, should not be used to constitute independent premises because that would entail non-legal reasoning. To qualify as legally relevant, they must always be used in connection with legal norms, by giving them a certain meaning, especially when they are indeterminate.

Thus, although the legal context is a formalized framework, in judicial proceedings there is also room for multi-modal argumentation. In this respect, so-called unclear legal cases, those with vague and ambiguous premises, are particularly interesting. In these, it is possible to discern loci or "traces" of the mentioned multi-modal argumentation. They communicate the message that, for a realistic account of legal argumentation at least, one needs to take into account modes beyond the traditionally accepted logical mode.

Stemming from a descriptive point of view, it is important to realize the presence of the alternate modes in legal argumentation since the legal logical mode is reductionist. From a normative aspect it is, however, difficult to say how much of such heuristics is allowed for decisions to be still considered legal. It seems that only a general principle can be given that they must be relevantly linked to legal norms and potential deviations from that are evaluated by competent legal authorities on a case by case basis. This is, however, the material for another topic to be discussed, of fallacies of multi-modal arguments in legal argumentation. 


\section{BIBLIOGRAPHY:}

Alexy, R. (1989). A Theory of Legal Argumentation. Oxford: Clarendon Press.

Barthes, R. (1967). Elements of Semiology. London: Jonathan Cape.

Bateman, J. A. (2014). Text and image. A critical introduction to the visual/verbal divide. London: Routledge.

Beck, G. (2012). The Legal Reasoning of the Court of Justice of the EU. Oxford and Portland, Oregon: Hart Publishing.

Blair, A. J. (2015). Probative norms for multimodal visual arguments. Argumentation, 29(2), 217-233.

Engisch, K. (1963). Logische Studien zur Gesetzensanwendung [Logical Studies of Law Application]. Heidelberg: Winter.

Feteris, E. (2017). Fundamentals of Legal Argumentation: A Survey of Theories on the Justification of Judicial Decisions (2nd Ed.). Dordrecht: Springer.

Forceville, C. (2020). Visual and Multimodal Communication: Applying the Relevance Principle. Oxford: Oxford University Press.

Gilbert, M. (1994). Multi-Modal Argumentation. Philosophy of the Social Sciences, 24(2), 159-177.

Gilbert, M. (1997). Coalescent Argumentation. Mahwah, New Jersey: Lawrence Erlbaum Associates, Publishers.

Groarke, L. (2017). Multimodality and the Law. In: Manzin, M., Puppo, F. and Tomasi, S. (eds.), Multimodality and Reasonableness in Judicial Rhetoric. Studies on Argumentation \& Legal Philosophy 2 (5-32). Trento: Università degli studi di Trento, Quaderni della Facoltà di giurisprudenza.

Groarke, L. and Tindale, C. (2004). Good Reasoning Matters! A Constructive Approach to Critical Thinking. Don Mills, Ontario: Oxford University Press.

Guastini, R. (2014). La sintassi dei diritto. Torino: G. Giappichelli editore.

Jewitt, C. (ed.). (2014). The Routledge Handbook of Multimodal Analysis (2nd ed.). London: Routledge.

Jung, C. G. (1971). Psychological Types. London: Routledge.

Kahneman, D. (2011). Thinking, Fast and Slow. London: Penguin Books.

Kelsen, H. (1989). Pure Theory of Law. Gloucester, Massachusetts: Peter Smith.

King, R. and Spagnola, L. J. (2012). The Riot Within: My Journey from Rebellion to Redemption. New York: HarperOne.

Kjeldsen, J. E. (2015). The Study of Visual and Multimodal Argumentation. Argumentation, 29(2), 115-132.

Kjeldsen, J. E. (2016). Symbolic condensation and thick representation in visual and multimodal communication. Argumentation and Advocacy, 52(4), 265-280.

Kjeldsen J. E. (2017). The rhetorical and argumentative potentials of press photography. In: Tseronis, A. and Forceville, C. (eds.) Multimodal Argumentation and Rhetoric in Media Genres (51-80). Amsterdam: John Benjamins Publishing Company.

Koon, S. C. and Deitz, R. (1992). Presumed Guilty: The Tragedy of the Rodney King Affair. Washington, D.C.: Regnery Gateway.

Kress, G. (2010). Multimodality: A Social Semiotic Approach to Contemporary Communicdation. London: Routledge.

Kress, G. and Van Leeuwen, T. (2001). Multimodal Discourse: The Modes and Media of Contemporary Communication. London: Arnold.

MacCormick, N. (2005). Rhetoric and The Rule of Law. A Theory of Legal Reasoning. Oxford: Oxford University Press.

Mercier, H. and Sperber, D. (2018). The Enigma of Reason, A New Theory of Human Understanding. Penguin Books: London. 
Novak, M. (2020a). Multi-modal argumentation and rhetoric in judicial proceedings. Argumentation and advocacy. 2020, 56(1), 41-60.

Novak, M. (2020b). Rooting Gilbert's multi-modal argumentation in Jung, and its extension to law. Informal logic, 40(3), 383-421.

Oyserman, D. (2001). Values: Psychological Perspectives. In: International Encyclopedia of the Social and Behavioral Sciences. Elsevier Science Ltd.

Perelman, C. and Olbrechts-Tyteca, L. (1969). The new rhetoric: A treatise on argumentation. Notre Dame: University of Notre Dame Press.

Thagard, P. (2013). The Brain and the Meaning of Life. Princeton: Princeton University Press.

Tindale, C. (2004). Rhetorical Argumentation, Principles of Theory and Practice. Thousand Oaks, California: Sage Publications.

Tseronis, A. and Forceville, C. (eds.) (2017). Multimodal Argumentation and Rhetoric in Media Genres. Amsterdam: John Benjamins.

Wróblewski, J. (1992). The Judicial Application of Law. Dordrecht: Springer Netherlands.

ECtHR, Rothe v. Austria, app. no. 6490/07, 4 December 2012.

ECtHR, Wirtschafts-Trend Zeitschriften-Verlagsgesellschaft m.b.H v. Austria, app. no. 58547/00, 27 October 2005.

Slovenia, Higher Court in Ljubljana, I Cp 3057/2013 (12 February 2014).

Slovenia, Supreme Court, II Ips 93/2015 (10 September 2015).

Slovenia, Constitutional Court, Up-407/14 (14 December 2016).

United States, Supreme Court of the United States, Smith v. United States, 508 U.S. 223 (1993) 
